\title{
Multiplicación in vitro de Eucalyptus globulus mediante sistema de inmersión temporal
}

\author{
In vitro multiplication of Eucalyptus globulus by temporary immersion system
}

\author{
Ricardo González a,b, Darcy Ríos a, Fabiola Avilés a, Manuel Sánchez-Olate a* \\ *Autor de correspondencia: ${ }^{a}$ Universidad de Concepción, Facultad de Ciencias Forestales y Centro de Biotecnología, Laboratorio de \\ Cultivo de Tejidos Vegetales, Concepción, Chile, tel.: 56-41-2204679, msanche@udec.cl \\ ${ }^{\text {b } U n i v e r s i d a d ~ d e ~ C o n c e p c i o ́ n, ~ F a c u l t a d ~ d e ~ C i e n c i a s ~ F o r e s t a l e s, ~ D o c t o r a d o ~ e n ~ C i e n c i a s ~ F o r e s t a l e s, ~ C o n c e p c i o ́ n, ~ C h i l e . ~}$
}

\begin{abstract}
SUMMARY
With the object of establishing mass production methods of Eucalyptus globulus, factors affecting its in vitro multiplication stage by temporary immersion were studied. For this, five microshoots per flask containing $250 \mathrm{~mL}$ of Murashige and Skoog medium were disposed. Factors such as immersion frequency (6, 12, 24, 48 h), immersion time (1, 2 and 3 min) and macronutrients concentration (25, 50 and $100 \%)$ were studied. In a second stage, the addition into medium of 6-bencylaminopurine (0, 2.2 and $4.4 \mu \mathrm{M})$, polyvinylpyrrolidone (0, 250 y $\left.500 \mathrm{mg} \mathrm{L}^{-1}\right)$ and sucrose concentration (43.8 and $\left.87.6 \mathrm{mM}\right)$ was analyzed. A completely random design with factorial arrangement was used in each stage. Variables evaluated were number of new shoots per flask, dry and fresh weight rate and final $\mathrm{pH}$ of culture medium. The best rate of multiplication and less hyperhydration was obtained with immersion time of 2 min, a frequency of 12 hours, macronutrients at $50 \%, 2.2 \mu \mathrm{mol}$ of 6-bencylaminopurine, $43.8 \mathrm{mM}$ of sucrose and $250 \mathrm{mg} \mathrm{L}{ }^{-1}$ of polyvinylpyrrolidone. Time and frequency of immersion interaction affects multiplication rate and microshoot hyperhydration. Use of 6-bencylaminopurine $(2,2 \mu \mathrm{M})$ and polyvinylpyrrolidone (250 $\left.\mathrm{mg} \mathrm{L}^{-1}\right)$ increases multiplication rate without influence on microshoot hyperhydration. A reduction on sucrose concentration decreases hyperhydration without affecting formation of new shoots.
\end{abstract}

Key words: hyperhydration, immersion frequency, immersion time, 6-bencylaminopurine, polyvinylpyrrolidone.

\section{RESUMEN}

Con el objeto de establecer metodologías de masificación de Eucalyptus globulus se analizaron factores que afectan la multiplicación in vitro de esta especie mediante el sistema de inmersión temporal. Para ello se dispusieron cinco microtallos por frasco, conteniendo $250 \mathrm{~mL}$ de medio Murashige y Skoog. Se estudiaron la frecuencia de inmersión $(6,12,24,48$ h), tiempo de inmersión (1, 2 y $3 \mathrm{~min}$ ) y concentración de macronutrientes (25, 50, $100 \%)$. También se estudió el efecto de la adición al medio de cultivo de 6-bencilaminopurina (0, 2,2 y 4,4 $\mu \mathrm{M})$, polivinilpirrolidona (0, 250 y $500 \mathrm{mg} \mathrm{L}^{-1}$ ) y concentración de sacarosa (43,8 y 87,6 mM). En cada ensayo se realizó un diseño completo aleatorio con arreglo factorial con tres repeticiones. Se evaluó número de brotes nuevos por frasco, razón de masa seca/masa fresca, $\mathrm{pH}$ final del medio de cultivo y porcentaje de brotes hiperhidratados. El tratamiento que presentó una mayor generación de brotes y menor hiperhidratación fue obtenido con un tiempo de inmersión de dos minutos, frecuencia cada 12 horas, concentración de macronutrientes al $50 \%$, 43,8 mM de sacarosa, 2,2 $\mu$ mol de 6-bencilaminopurina y 250 $\mathrm{mg} \mathrm{L}^{-1}$ de polivinilpirrolidona. La tasa de multiplicación de microtallos de E. globulus es significativamente mayor al aumentar el tiempo de inmersión de 1 a 2 minutos, así como al suplementar el medio de cultivo con 4,4 $\mu \mathrm{M}$ de 6-bencilaminopurina. Por otra parte, la tasa de multiplicación decae si la frecuencia de inmersión disminuye de ciclos cada 12 h a ciclos cada 48 h. Finalmente, la hiperhidratación de los tejidos aumenta al elevar la concentración de los macronutrientes y sacarosa, sin ser afectada por el nivel de antioxidante agregado al medio.

Palabras clave: hiperhidratación, frecuencia de inmersión, tiempo de inmersión, 6-bencilaminopurina, polivinilpirrolidona.

\section{INTRODUCCIÓN}

La morfogénesis está influenciada por el genotipo, y su expresión génica o fenotipo depende de las condiciones físicas y químicas del ambiente (Pierik 1997). Dentro de las condiciones físicas se encuentra el medio de cultivo, el que puede ser líquido o gelificado (Paeket al. 2005). La principal diferencia entre ambas condiciones es su influencia en la absorción de nutrientes; el medio líquido permite la absorción por toda la superficie del tejido, influyendo en el desarrollo y estructura de éstos (Preil 2005).
Dentro de los métodos de multiplicación en medio líquido se encuentran los sistemas de inmersión temporal (SIT), los cuales permiten la automatización de la etapa de multiplicación in vitro, en contraste con el medio tradicional semisólido, lo que trae consigo una disminución en los costos de mano de obra y, por ende, en los costos de producción (Ziv 2000). En varias especies y en especial en Eucalyptus spp., el cultivo en sistemas de inmersión temporal ha logrado un aumento en la tasa de multiplicación y reducción en el tiempo de multiplicación comparado con el medio semisólido, y una menor presencia de callo en 
hojas y tallos (Castro y González 2002, McAlisteret al. 2005). Las principales desventajas del cultivo en sistemas de inmersión temporal son el alto grado de hiperhidratación y la oxidación de los tejidos (Etienne y Berthouly 2002, Ziv 2005), aspectos que han sido asociados con factores tales como el tiempo, la frecuencia de inmersión y la concentración de carbohidratos y macronutrientes en el medio (Castro y González 2002). Al respecto, McAlisteret al. (2005) observaron una disminución de las tasas de multiplicación en tratamientos con una mayor frecuencia de inmersión lo cual estaría asociado a la presencia de estrés oxidativo, lo que podría sugerir un efecto de la concentración de sustancias antioxidantes en el medio.

Respecto a la multiplicación de microtallos de Eucalyptus spp. por medio de sistemas de inmersión temporal, Castro y González (2002) alcanzaron en Eucalyptus grandis Hill. un coeficiente de multiplicación de 11,5 brotes en seis semanas de cultivo. Por su parte, mediante el uso de este sistema, McAlisteret al. (2005) reprodujeron distintos clones de Eucalyptus spp., duplicando la tasa de multiplicación en la mitad del tiempo, comparado con el método tradicional en medio semisólido. En este contexto, la tasa de multiplicación está influenciada por el tipo y concentración de citoquinina utilizada, como es el caso reportado por Roels et al. (2005) en Musa spp.

Los antecedentes expuestos indican que en sistemas de inmersión temporal la multiplicación de microtallos aumenta con la frecuencia y duración de la inmersión. Este comportamiento también puede estar influido por la concentración de hormonas en el medio de cultivo. Por otro lado, este aumento de la frecuencia y duración de la inmersión, unido a mayores concentraciones hormonales en el medio de cultivo, pueden favorecer la aparición de fenómenos de hiperhidratación en los microtallos. Con el fin de optimizar la multiplicación in vitro de Eucalyptus globulus Labill. mediante el sistema de inmersión temporal, el objetivo de este trabajo es analizar el efecto de cambios en la frecuencia y duración de la inmersión de los microtallos, así como de cambios en la concentraciones de macronutrientes, sacarosa, antioxidantes y hormonas en el medio de cultivo, sobre las tasas de multiplicación e hiperhidratación de estos.

\section{MÉTODOS}

El ensayo se realizó en el laboratorio de cultivo de tejidos de la Facultad de Ciencias Forestales, en el Centro de Biotecnología de la Universidad de Concepción. Se utilizaron semillas de E. globulus procedentes de Cauquenes ( $\left.35^{\circ} 47^{\prime} \mathrm{S}, 72^{\circ} 5^{\prime} \mathrm{O}\right)$. La desinfección y la fase de germinación se realizó según Gómez et al. (2006). En la fase de multiplicación se utilizaron frascos de vidrio de $200 \mathrm{~mL}$ cada uno con aproximadamente $20 \mathrm{~mL}$ de medio de cultivo MS (Murashige y Skoog 1962) el cual fue suplementado con 2,7 $\mu \mathrm{M}$ 6-bencilaminopurina (BAP), 0,05 $\mu \mathrm{M}$ ácido naftalen acético (ANA), 87,6 mM sacarosa y
$7 \mathrm{~g} \mathrm{~L}^{-1}$ Agar Sigma ${ }^{\circledR}$. El pH fue ajustado a 5,8 con ácido clorhídrico e hidróxido de sodio. Posteriormente, el medio de cultivo fue autoclavado a $120{ }^{\circ} \mathrm{C}$ y una atmósfera de presión durante 20 minutos. Después se dispusieron cinco microtallos de 1,5 cm de longitud por frascos provenientes de la fase de germinación, bajo cámara de flujo laminar, trasladándose posteriormente a una cámara de crecimiento bajo fotoperíodo de $16 \mathrm{~h}$, temperatura de $24 \pm 1{ }^{\circ} \mathrm{C}$ en el día y $22 \pm 1{ }^{\circ} \mathrm{C}$ en la noche, con una intensidad lumínica de $30 \mu \mathrm{mol} \mathrm{s}^{-1} \mathrm{~m}^{-2}$. Se realizaron dos subcultivos cada seis semanas.

Ensayo de inmersión temporal. Se utilizó un sistema de inmersión temporal basado en el modelo propuesto por Escalona et al. (1998) (figura 1). Se utilizaron filtros de aire de $2 \mu \mathrm{m}$ en cada entrada y salida de aire de los frascos de medio y cultivo, se colocó una malla de plástico a $5 \mathrm{~mm}$ medidos desde el fondo del frasco sobre la cual se dispusieron los microtallos para evitar el contacto de éstos con cualquier posible remanente de medio en el fondo el recipiente. Para el cambio del sentido del movimiento de aire, se utilizó una electroválvula 5/2 (JelPC®, modelo 4v21008), la presión de aire fue regulada a dos bares mediante un regulador de presión (JelPC $®$, modelo Jar 2000). Se realizaron dos ensayos (cuadro 1), como material vegetal se utilizaron cinco microtallos E. globulus de 1,5 cm de longitud provenientes del segundo subcultivo del material cultivado en medio semisólido, los cuales se dispusieron en frascos $600 \mathrm{~mL}$. Se empleó medio MS, no obstante, la concentración de macronutrientes, 6-bencilaminopurina, sacarosa y polivinilpirrolidona (PVP) varió de acuerdo al ensayo evaluado (cuadro 1). Para todos los tratamientos, el volumen de medio de cultivo utilizado por frasco fue de $200 \mathrm{~mL}$.

Se utilizó un diseño completo aleatorio con arreglo factorial con tres repeticiones. Cada repetición estuvo compuesta por un frasco con cinco microtallos. Se evaluó: número de brotes nuevos por frasco correspondientes a la diferencia entre los brotes iniciales mayores a $5 \mathrm{~mm}$ y finales mayores a $5 \mathrm{~mm}$; porcentaje de masa seca/masa fresca, la estimación de masa seca se determinó mediante el secado en una estufa a $105{ }^{\circ} \mathrm{C}$ hasta peso constante; $\mathrm{pH}$ final del medio mediante un $\mathrm{pH}$-metro (marca Orion 3 Star) y porcentaje de hiperhidratación, correspondiente a la razón entre número de brotes mayores a $5 \mathrm{~mm}$ con aspecto cristalino y el número de brotes finales mayores a $5 \mathrm{~mm}$.

Los datos fueron analizados mediante ANDEVA y para establecer los tratamientos en los que existieron diferencias estadísticas se aplicó la prueba de Tukey para comparaciones múltiples con nivel de significancia de $P<0,05$. Para ello se utilizó el software Statistica versión 6.0.

\section{RESULTADOS}

Ensayo 1. En E. globulus, la variable número de brotes nuevos por frasco se vio altamente afectada por la interac- 
Cuadro 1. Descripción de los factores en cada ensayo (4 semanas), donde (*) indica el factor estudiado en el ensayo correspondiente. Description of factors of each experiment, where $(*)$ indicates factor studied at correspondent experiment.

\begin{tabular}{|c|c|c|}
\hline Factor & Ensayo 1 & Ensayo 2 \\
\hline Frecuencia inmersión (h) & $(*) 12,24,36$ y 48 & 12 \\
\hline Tiempo inmersión (min) & $\left(^{*}\right) 1,2$ y 3 & 2 \\
\hline Concentración macronutrientes (\%) & (*) 25, 50 y 100 & 50 \\
\hline 6-bencilaminopurina, BAP ( $\mu \mathrm{M})$ & 2,2 & $(*) 0,2,2$ y 4,4 \\
\hline Polivinilpirrolidona, PVP (mg L $\left.{ }^{-1}\right)$ & 0 & (*) 0,250 y 500 \\
\hline Sacarosa (mM) & 87,6 & $(*) 87,6$ y 43,8 \\
\hline
\end{tabular}

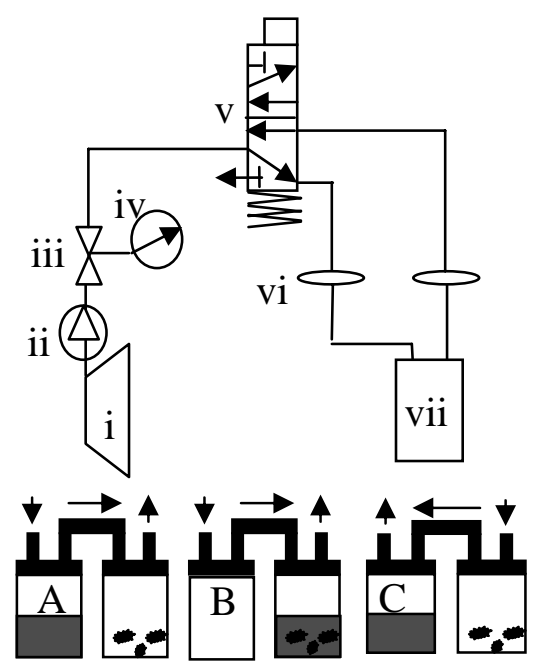

Figura 1. Modelo de sistema inmersión temporal líquido BIT ${ }^{\circledR}$ propuesto por Escalona et al. (1998). i) Compresor; ii) flujo de aire; iii) regulador de presión; iv) manómetro; v) electroválvula $5 / 2$; vi) filtros de aire; vii) frascos de $600 \mathrm{~mL}$. A) Ingreso de aire estéril, dirección frasco con medio hacia frasco con microtallos. B) paso de líquido desde frasco con medio a frasco con microtallos por efecto de la presión de aire. C) después de un periodo determinado se invierte el flujo de aire para traspasar el medio líquido al frasco original.

Temporary immersion system proposed by Escalona et al. (1998): i) compressor, ii) air flux, iii) pressure regulator, iv) manometer, v) electrovalve, vi) air filters, vii) $600 \mathrm{~mL}$ flasks. A) Sterile air entrance, from fresh medium flash to microshoots flask. B) Liquid movement from fresh medium flash to microshoots flask by air pressure. C) After a determined time, the air flux is inverted to transfer liquid medium to original flask.

ción de los factores tiempo de inmersión y concentración de macronutrientes (cuadro 2). En general, se presentó una tendencia de aumento del número de brotes nuevos por frasco al aumentar la concentración de macronutrientes, obteniéndose diferencias significativas $(P<0,05)$ entre las concentraciones al 25 y las de 50 y $100 \%$ en el medio MS, independiente del tiempo de inmersión. Con respecto a este último, existió un aumento significativo $(P<0,05)$ entre la inmersión de uno y las de dos y tres minutos, siendo más acentuada en aquellas que tuvieron medios con ma-
Cuadro 2. Número de brotes nuevos por frasco según interacción en primer grado del tiempo de inmersión y concentración de macronutrientes.

Number of new shoots by flash of first grade interaction between immersion time and macronutrients concentration.

\begin{tabular}{ccc}
\hline $\begin{array}{c}\text { Tiempo inmersión } \\
(\mathrm{min})\end{array}$ & $\begin{array}{c}\text { Concentración } \\
\text { macronutrientes (\%) }\end{array}$ & $\begin{array}{c}\mathrm{N}^{\circ} \text { brotes nuevos } \\
\text { por frasco }\end{array}$ \\
\hline \multirow{2}{*}{1} & 25 & $15,9 \pm 5,6 \quad \mathrm{~d}$ \\
& 50 & $25,5 \pm 8,7 \quad$ c \\
& 100 & $26,5 \pm 5,0 \quad$ c \\
25 & $30,8 \pm 7,1$ bc \\
& 100 & $35,9 \pm 9,1$ ab \\
& 25 & $37,8 \pm 7,9$ a \\
3 & 50 & $17,3 \pm 5,2 \quad$ d \\
& 100 & $34,3 \pm 6,7$ bc \\
\end{tabular}

En cada columna, valores con letras diferentes indican diferencias significativas (Tukey, $P<0,05$ ).

yor concentración de macronutrientes. Se observó que los mejores resultados en número de brotes nuevos por frasco fueron aquellos con un tiempo de inmersión de dos minutos y concentraciones de 50 y $100 \%$, y el tratamiento con un tiempo de inmersión de tres minutos y concentración de macronutrientes del $100 \%$, obteniéndose más de un $116 \%$ de número de brotes nuevos por frasco que el tratamiento con un minuto de tiempo de inmersión y $25 \%$ de concentración de macronutrientes.

Al analizar el factor principal frecuencia de inmersión para el número de brotes nuevos por frasco, los mejores tratamientos fueron aquellos con una frecuencia cada 6 y 12 horas, los cuales obtuvieron $30,7 \pm 8$ y 33,7 \pm 10 , 3 brotes nuevos por frasco, respectivamente. Estos tratamientos presentaron diferencias significativas con la frecuencia de inmersión cada dos días (48 h), la cual obtuvo un valor de 20,3 \pm 8,2 brotes nuevos por frasco (datos no mostrados).

Respecto al porcentaje de masa seca/masa fresca (cuadro 3), en relación a la interacción frecuencia de inmersión y concentración de macronutrientes, existió una tendencia de aumento de la cantidad de materia seca en los trata- 
Cuadro 3. Relación porcentaje de masa seca/masa fresca final y pH final según interacción en primer grado de la frecuencia de inmersión y concentración de macronutrientes.

Dry weight/fresh final weight rate regarding first grade interaction between immersion frequency and macronutrients concentration.

\begin{tabular}{cccccc}
\hline $\begin{array}{c}\text { Frecuencia de } \\
\text { inmersión (h) }\end{array}$ & $\begin{array}{c}\text { Concentración de } \\
\text { macronutrientes (\%) }\end{array}$ & $\begin{array}{c}\text { MS/MF } \\
\text { (\%) }\end{array}$ & pH & \\
\hline \multirow{2}{*}{6} & 25 & $43,3 \pm 3,9$ & $\mathrm{f}$ & $4,38 \pm 0,04$ & ef \\
& 50 & $42,5 \pm 4,2$ & $\mathrm{f}$ & $4,30 \pm 0,07$ & $\mathrm{~g}$ \\
& 100 & $42,0 \pm 2,5$ & $\mathrm{f}$ & $4,34 \pm 0,04$ & fg \\
& 25 & $55,3 \pm 3,7$ & $\mathrm{~d}$ & $4,46 \pm 0,09$ & bc \\
& 50 & $50,8 \pm 2,6$ & e & $4,47 \pm 0,06$ & cd \\
& 100 & $51,8 \pm 3,2$ & de & $4,39 \pm 0,07$ & ef \\
& 25 & $64,4 \pm 2,9$ & ab & $4,57 \pm 0,02$ & ab \\
& 50 & $62,8 \pm 3,1$ & abc & $4,52 \pm 0,05$ & c \\
& 100 & $61,1 \pm 2,9$ & bc & $4,45 \pm 0,06$ & de \\
& 25 & $65,5 \pm 2,4$ & a & $4,63 \pm 0,03$ & a \\
& 50 & $65,0 \pm 3,4$ & a & $4,62 \pm 0,06$ & ab \\
& 100 & $60,3 \pm 2,3$ & c & $4,50 \pm 0,03$ & c \\
\hline
\end{tabular}

MS/MF: relación porcentaje de masa seca/masa fresca final. En cada columna, letras diferentes indican diferencias significativas (Tukey, $P<0,05)$.

mientos con menor frecuencia de inmersión (24 y 48 h) con respecto a los de 6 y $12 \mathrm{~h}$, y un aumento de materia seca al disminuir la concentración de macronutrientes a un 50 y $25 \%$ en estas frecuencia de inmersión. Con respecto al efecto del tiempo de inmersión, el tratamiento significativamente mejor fue aquel con una inmersión de un minuto, que obtuvo un valor de 58,4 \pm 7,9 \% de masa seca/ masa fresca en relación a los tratamientos con un tiempo de inmersión de dos o tres minutos, los que obtuvieron una proporción masa seca/masa fresca de 54,2 \pm 9,5 y 53,6 \pm $10,5 \%$, respectivamente (datos no mostrados).

Se observó que el comportamiento de la variable $\mathrm{pH}$ (cuadro 3) es similar a la razón porcentaje de masa seca/ masa fresca, donde los medios con mayor frecuencia de inmersión (6 h) fueron los más acidificados. Por otro lado, aunque la concentración de macronutrientes interactúa con la frecuencia de inmersión los resultados muestran que la disminución del $\mathrm{pH}$ en el medio de cultivo es menor cuando la concentración de macronutrientes disminuye. El factor tiempo de inmersión tendió a comportarse similar que la frecuencia de inmersión, mostrándose una mayor acidificación del medio en la medida que aumentó el tiempo de inmersión (tres minutos), que obtuvo un $\mathrm{pH}$ de $4,44 \pm 0,12$ significativamente menor a los tratamientos con un tiempo de inmersión de uno y dos minutos, los que obtuvieron un valor de $\mathrm{pH}$ de 4,50 $\pm 0,11$ y $4,47 \pm 0,10$ respectivamente (datos no mostrados). En general, un mayor tiempo de contacto de los microtallos con el medio de cultivo, ya sea aumentando la frecuencia de inmersión o bien aumentando el tiempo de duración de cada inmersión, genera una mayor acidificación del medio líquido.
La hiperhidratación de los brotes aumenta a medida que se incrementa la concentración de macronutrientes en el medio y el tiempo de inmersión (cuadro 4), estas diferencias en concentración de macronutrientes mostraron una disminución si el tiempo de inmersión aumenta.

Por otro lado, la hiperhidratación de los brotes respecto dela frecuencia de inmersión tuvo un comportamiento

Cuadro 4. Porcentaje de hiperhidratación de brotes según interacción en primer grado de tiempo de inmersión y concentración de macronutrientes.

Hyperhydration percentage of shoots regards first grade interaction between immersion frequency and macronutrients concentration.

\begin{tabular}{ccc}
\hline $\begin{array}{c}\text { Tiempo de } \\
\text { inmersión } \\
(\text { min) }\end{array}$ & $\begin{array}{c}\text { Concentración de } \\
\text { macronutrientes } \\
(\%)\end{array}$ & $\begin{array}{c}\text { Hiperhidratación } \\
(\%)\end{array}$ \\
\hline \multirow{2}{*}{1} & 25 & $31,0 \pm 10,0$ f \\
& 50 & $41,0 \pm 15,0$ de \\
& 100 & $45,1 \pm 9,3$ cd \\
2 & 50 & $47,9 \pm 12,2$ ef \\
& 100 & $53,2 \pm 11,9$ ab \\
& 25 & $36,4 \pm 11,6$ d \\
3 & 50 & $51,8 \pm 13,7$ ab \\
& 100 & $56,2 \pm 10,5$ a \\
\hline
\end{tabular}

En cada columna, valores con letras diferentes indican diferencias significativas (Tukey, $P<0,05$ ). Análisis con datos transformados arcoseno $\sqrt{ }(\mathrm{x} \% / 100)$. 
similar al pH, ya que a medida que se aumentó la frecuencia de inmersión se incrementó la hiperhidratación de los brotes. Los tratamientos con mayor hiperhidratación de los brotes fueron los con seis $(59,5 \pm 8,9 \%)$ y $12(53,2$ $\pm 11,4 \%$ ) horas de frecuencia de inmersión, presentando diferencias significativas entre ellos y con el tratamiento con menor hiperhidratación de los brotes (48 h frecuencia de inmersión) con valores de 32,1 \pm 9,5 \% (datos no mostrados).

Ensayo 2. En el cuadro 5 se aprecia que para el factor concentración de sacarosa no existieron diferencias significativas entre las distintas concentraciones para el número de brotes nuevos por frasco, pero sí entre la razón porcentaje de masa seca/masa fresca y $\mathrm{pH}$. Se obtuvo hasta un $9 \%$ más de masa seca/masa fresca, menor acidificación en el medio y menor hiperhidratación de los brotes en el tratamiento con 43,8 mM de sacarosa que en el tratamiento con 87,6 mM. Con respecto a la aplicación de citoquinina (cuadro 5), la generación de brotes en E. globulus estuvo altamente influenciada por la presencia o ausencia de 6-bencilaminopurina, produciendo $118 \%$ más de brotes en el tratamiento con 4,4 $\mu \mathrm{M}$ que en el control sin 6-bencilaminopurina. Sin embargo, no se produjeron diferencias significativas $(P>0,05)$ al aumentar de 2,2 a 4,4 $\mu \mathrm{M}$ 6-bencilaminopurina. No obstante, en el tratamiento con 4,4 $\mu \mathrm{M}$ de 6-bencilaminopurinase observó significativamente más brotes hiperhidratadoscon respecto a los tratamientos con 2,2 y sin 6-bencilaminopurina. Los resultados mostraron que el $\mathrm{pH}$ no se vio influenciado por los distintos niveles de 6-bencilaminopurina.
Al analizar el efecto principal de la aplicación de antioxidante (cuadro 5), existió un aumento en el número de brotes nuevos por frasco entre el tratamiento sin antioxidante y la adición de $250 \mathrm{mg} \mathrm{L}^{-1}$ de polivinilpirrolidona, pero se observó una disminución en la proliferación al duplicar la concentración de antioxidante $\left(500 \mathrm{mg} \mathrm{L}^{-1}\right)$. Por otro lado, al aumentar la concentración de polivinilpirrolidona a $500 \mathrm{mg} \mathrm{L}^{-1}$ aumentó significativamente $(P<0,05)$ la acidificación del medio y disminuyó la relación porcentaje de masa seca/masa fresca en relación al tratamiento sin polivinilpirrolidona. El porcentaje de hiperhidratación de los brotes no se vio afectado por la aplicación de antioxidante.

En general, altas frecuencias de inmersión y concentraciones de macronutrientes (figuras 2A y $2 \mathrm{~B}$ ) inducen mayor número de brotes respecto de una menor frecuencia de inmersión y concentración de macronutrientes, pero se produce hiperhidratación de los microtallos. Por otro lado, si se disminuye la frecuencia de inmersión y concentración de sacarosa, manteniendo el suplemento con citoquinina (6-bencilaminopurina) e incorporando antioxidante, la generación de brotes se mantiene alta y se mejora la calidad del tejido, obteniéndose microtallos menos hiperhidratados (figuras 2C y 2D).

En los cortes histológicos foliares y caulinares (figura 3) el tejido caulinar de frecuencias bajas (figura 3A) se caracterizó por poseer células más pequeñas a nivel de la médula con respecto a los de mayor frecuencia de inmersión (figura 3B). Por otro lado, en tratamientos de menor frecuencia de inmersión (figuras $3 \mathrm{C}$ y $3 \mathrm{E}$ ), se apreció una clara conformación del tejido componente del mesófilo y el haz vascular, no así los tratamientos con mayor frecuen-

Cuadro 5. Número de brotes nuevos por frasco (NBNF), relación porcentaje de peso seco/peso fresco final (MS/MF), pH final del medio de cultivo y porcentaje de hiperhidratación, según niveles de sacarosa, 6-bencilaminopurina y polivinilpirrolidona.

Number of new shoots per flask (NBNF), percentage ratio of dry weight/final fresh weight (MS/MF), final pH of the culture medium and rate of hyperhydration, according to levels of sucrose, 6-benzylaminopurine and polyvinylpyrrolidone.

\begin{tabular}{|c|c|c|c|c|c|c|c|}
\hline Factores & \multicolumn{2}{|l|}{ NBNF } & MS/MF (\%) & \multicolumn{2}{|l|}{$\mathrm{pH}$} & \multicolumn{2}{|c|}{ Hiperhidratación (\%) } \\
\hline \multicolumn{8}{|c|}{ Sacarosa (mM) } \\
\hline 43,8 & $32,9 \pm 11,8$ & a & $74,0 \pm 6,8 \quad$ a & $4,62 \pm 0,05$ & a & $49,4 \pm 13,3$ & $\mathrm{~b}$ \\
\hline 87,6 & $33,5 \pm 16,9$ & a & $67,6 \pm 4,9 \quad b$ & $4,58 \pm 0,06$ & $\mathrm{~b}$ & $56,3 \pm 12,2$ & a \\
\hline \multicolumn{8}{|c|}{ 6-bencilaminopurina $(\mu \mathrm{M})$} \\
\hline 0,0 & $19,6 \pm 11,3$ & $\mathrm{~b}$ & $75,3 \pm 5,2 \quad a$ & $4,62 \pm 0,06$ & a & $45,3 \pm 11,6$ & $\mathrm{~b}$ \\
\hline 2,2 & $37,1 \pm 11,2$ & a & $73,4 \pm 4,1 \quad$ a & $4,60 \pm 0,06$ & a & $51,4 \pm 12,7$ & $\mathrm{~b}$ \\
\hline 4,4 & $42,9 \pm 9,1$ & a & $63,7 \pm 3,7 \quad b$ & $4,59 \pm 0,06$ & a & $61,9 \pm 9,6$ & a \\
\hline \multicolumn{8}{|c|}{ Polivinilpirrolidona (mg L ${ }^{-1}$ ) } \\
\hline 0 & $31,6 \pm 13,9$ & $\mathrm{~b}$ & $72,0 \pm 6,2 \quad a$ & $4,62 \pm 0,05$ & a & $55,8 \pm 14,7$ & a \\
\hline 250 & $43,2 \pm 11,2$ & a & $70,8 \pm 7,5 \quad a b$ & $4,62 \pm 0,05$ & a & $50,4 \pm 11,4$ & a \\
\hline 500 & $24,8 \pm 12,2$ & c & $69,6 \pm 6,7 \quad b$ & $4,56 \pm 0,07$ & $\mathrm{~b}$ & $52,5 \pm 13,3$ & a \\
\hline
\end{tabular}

NBNF: número de brotes nuevos por frasco; PS/PF: relación de porcentaje de peso seco/peso fresco final. En cada columna, letras diferentes indican diferencias significativas (Tukey, $P<0,05$ ). 


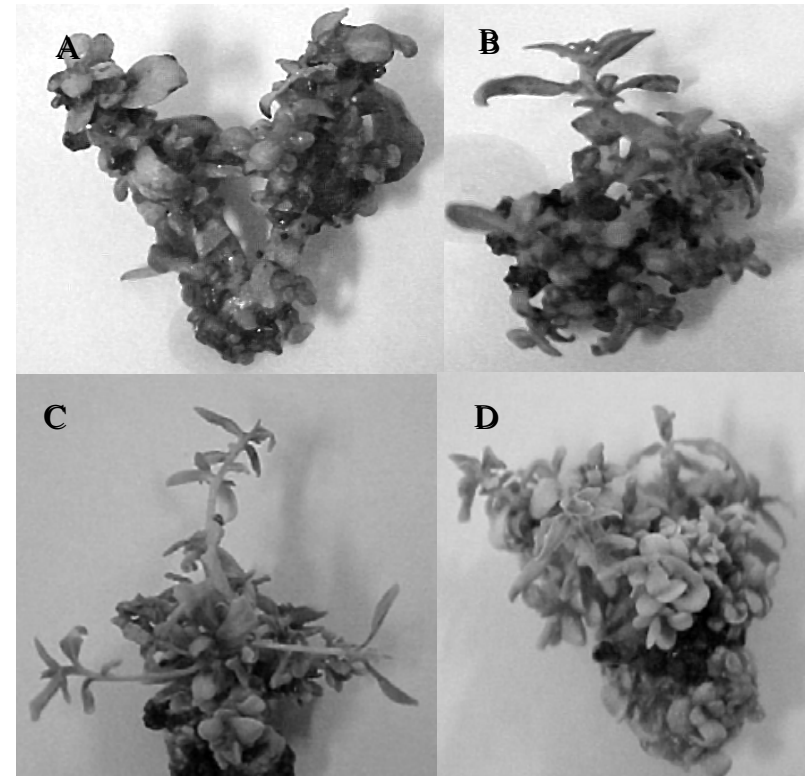

Figura 2. Micropropagación de E. globulus mediante el sistema de inmersión temporal. A) Microtallos en la etapa 1 después de 28 días en medio MS, con una frecuencia de inmersión de 6 h, tiempo de inmersión de $1 \mathrm{~min}, 2,2 \mu \mathrm{M}$ de 6-bencilaminopurina (BAP) y macronutrientes al $100 \%$. B) Microtallos en la etapa 1 después de 28 días en medio MS con una frecuencia de inmersión de 12 h, tiempo de inmersión de $3 \mathrm{~min}, 2,2 \mu \mathrm{M}$ de 6-bencilaminopurina y macronutrientes al $100 \%$. C) Microtallos en la etapa 2 después de 28 días con una frecuencia de inmersión de 24 h, tiempo de inmersión de 1 min, en medio MS suplementado con 43,8 $\mathrm{mM}$ de sacarosa, 4,4 $\mu \mathrm{M}$ de 6-bencilaminopurina y $250 \mathrm{mg} \mathrm{L}^{-1}$ de polivinilpirrolidona (PVP). D) Microtallos en la etapa 2 después de 28 días con una frecuencia de inmersión de 24 h, tiempo de inmersión de 1 min, en medio MS suplementado con 43,8 $\mathrm{mM}$ de sacarosa, 2,2 $\mu \mathrm{M}$ de 6-bencilaminopurinay $250 \mathrm{mg} \mathrm{L}^{-1}$ de polivinilpirrolidona.

Micropropagation of E. globulus by temporary immersion system. A) Microshoots at stage 1 after 28 days at MS medium with an immersion frequency of $6 \mathrm{~h}$, immersion time of $1 \mathrm{~min}, 2.2 \mu \mathrm{M}$ of 6-benzylaminopurine and macronutrients at $100 \%$. B) Microshoots at stage 1 after 28 days at MS medium with an immersion frequency of $12 \mathrm{~h}$, immersion time of $3 \mathrm{~min}, 2.2 \mu \mathrm{M}$ of 6-benzylaminopurine and macronutrients at $100 \%$. C) Microshoots at stage 2 after 28 days with an immersion frequency of $24 \mathrm{~h}$, immersion time of $1 \mathrm{~min}, 4.4 \mu \mathrm{M}$ of 6-benzylaminopurine, $43 \mathrm{mM}$ of sucrose and $250 \mathrm{mg} \mathrm{L}^{-1}$ of polyvinylpyrrolidone. D) Microshoots at stage 2 with an immersion frequency of $24 \mathrm{~h}$, immersion time of $1 \mathrm{~min}, 2.2 \mu \mathrm{M}$ of 6-benzylaminopurine, $43 \mathrm{mM}$ of sucrose and $250 \mathrm{mg} \mathrm{L}^{-1}$ of polyvinylpyrrolidone.

cia de inmersión, en los cuales el contraste entre parénquima empalizada y el parénquima esponjoso no se apreció claramente (figura 3D) y el cilindro vascular apareció con un bajo nivel de diferenciación.

\section{DISCUSIÓN}

La utilización de sistemas de inmersión temporal en el cultivo in vitro de E. globulus origina altas tasas de

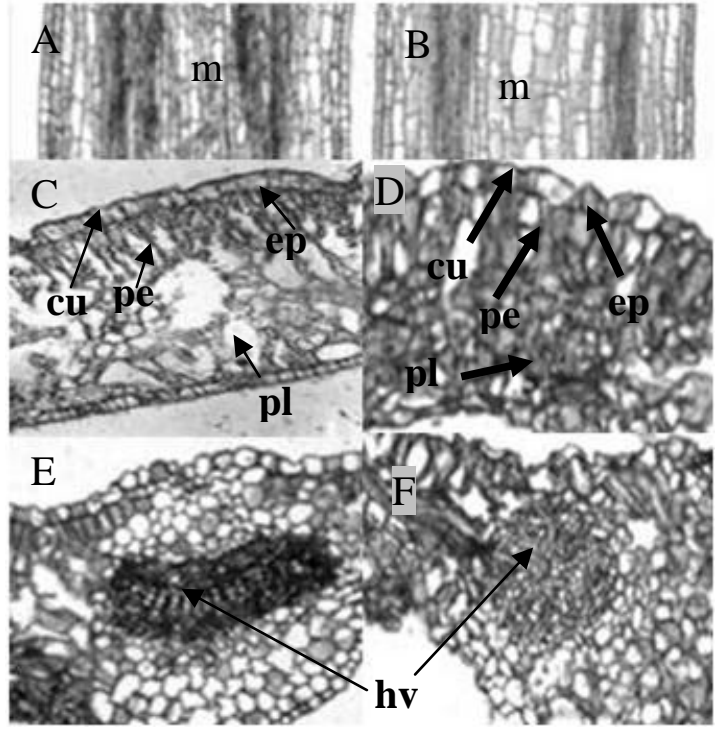

Figura 3. Histología foliares y caulinares de Eucalyptus globulus de tratamiento con tiempo de inmersión de 1 min, en medio MS suplementado con 43,8 $\mathrm{mM}$ de sacarosa, 2,2 $\mu \mathrm{M}$ de 6-bencilaminopurina y $250 \mathrm{mg} \mathrm{L}^{-1}$ de polivinilpirrolidona. A y B, segmento caulinar generado en frecuencia de inmersión cada 24 y cada $6 \mathrm{~h}$ respectivamente; $\mathrm{C}$ y D, segmento foliar generado en frecuencia de inmersión cada 24 y cada 6 h respectivamente; E y F, haz vascular generado en frecuencia de inmersión cada 24 y cada 6 h, respectivamente. $\mathrm{m}$ = médula; $\mathrm{cu}=$ cutícula; $\mathrm{ep}=$ epidermis; pe = parénquima empalizada; $\mathrm{pl}$ = parénquima esponjoso; hv = haz vascular central hoja.

Leaf and Stem histology of Eucalyptus globulus at treatment with 1 min of immersion, on MS medium supplemented with $43.8 \mathrm{mM}$ of sucrose, $2.2 \mu \mathrm{M}$ of 6-benzylaminopurine and $250 \mathrm{mg} \mathrm{L}^{-1}$ of polyvinylpyrrolidone. A and B, stem segment generated at immersion frequency each 24 and 6 h, respectively. C and D, Leaf segment generated at immersion frequency each 24 and $6 \mathrm{~h}$, respectively. E and F, vascular bundle generated at immersion frequency each 24 and 6 h, respectively. $\mathrm{m}=$ pith; $\mathrm{cu}$ = cuticle; ep = epidermis; $\mathrm{pe}=$ palisade parenchyma; $\mathrm{pl}$ = spongy parenchyma; hv = central vascular bundle of leaf.

proliferación de brotes (cuadros 2 y 5). Estos resultados concuerdan con los obtenidos por McAlisteret al. (2005), quienes obtuvieron más del doble de generación de brotes con respecto al medio semisólido en diferentes clones de Eucalyptus spp. Según Preil (2005), este aumento se puede deber principalmente a que la absorción de nutrientes y reguladores del crecimiento es por toda la superficie del tejido, lo que puede maximizar el desarrollo del explanto. Por otro lado, Bouman y Tiekstra (2005) postulan que los precipitados se redisuelven en el medio líquido, debido a una disminución en el pH o por la absorción por la planta de componentes disueltos en el medio y el cambio resultante en el equilibrio de disociación, lo que provoca la solubilización de los precipitados, a diferencia de los medios con agar donde sólo una parte pequeña del medio presenta estos cambios, por lo cual existe una acumulación de precipitados. La formación de nuevos brotes en relación a absorción de los nutrientes queda demostrada 
con los resultados de este estudio, al observar la tendencia de aumento de brotes nuevos al aumentar la concentración de macronutrientes, la cual, además, tuvo relación con el tiempo de inmersión, donde el tiempo de inmersión más bajo también provocó una disminución del número de brotes nuevos por frasco aún en altas concentraciones de macronutrientes (cuadro 2). Así mismo, una menor frecuencia de inmersión y, por tanto, menor tiempo de contacto de los tejidos con el medio, también se reflejó en una disminución del número de brotes nuevos por frasco.

El principal problema observado en la utilización del sistema de inmersión temporal para la proliferación de E. globulus es la hiperhidratación de los tejidos, principalmente a nivel del mesofilo y haz vascular foliar, lo cual en este estudio se evidenció sobre todo en los tratamientos con mayor frecuencia de inmersión (figura 3), datos que concuerdan con los obtenidos por Castro y González (2002) en E. grandis. En general, en los sistemas de inmersión temporal, los factores gravitantes que influyen tanto en la proliferación como en la hiperhidratación de los tejidos son la frecuencia de inmersión y el tiempo de inmersión (Berthouly y Etienne 2005). Esto puede estar dado por la formación de una película acuosa en el tejido, lo que podría interferir en el intercambio gaseoso entre el tejido exterior o superficie celular, ya que según Jackson (2003) las tasas de difusión de gas son aproximadamente 10.000 veces más lentas en el agua que en el aire, según estos autores el intercambio gaseoso en la fotosíntesis y respiración con altas frecuencias de inmersión, es reducido. Fujiwara y Kozai (1995) encontraron que el aumento de la cantidad de aire evita brotes hiperhidratados al utilizar medio líquido. Por otro lado, Martreet al. (2001) determinaron que la inmersión induce un estrés oxidativo importante en cultivos de callo de Hevea brasiliensis Muell. Este estrés oxidativo puede explicar las diferentes tasas de proliferación según la interacción de la concentración de macronutrientes y el tiempo de inmersión en E. globulus.

El pH final del medio mostró, en general, una disminución significativa en tratamientos con mayor frecuencia de inmersión y mayor concentración de macronutrientes (cuadro 3). Al respecto, Ramage y Williams (2002) relacionan el nivel de amonio en el medio con la acidificación del medio. En este caso, tratamientos con altas frecuencias de inmersión y por tanto asociadas a mayor exposición de los tejidos al contacto con el medio provocaron una mayor acidificación del medio de cultivo. Este aumento de acidificación de los tejidos al permanecer más tiempo sumergidos en medio líquido aplica para comprender también el comportamiento del $\mathrm{pH}$ respecto al tiempo de inmersión, donde el mayor tiempo de inmersión presentó un aumento significativo de la acidificación del medio de cultivo.

En este estudio, la aplicación de citoquininas al medio de cultivo tuvo un efecto positivo en la generación de nuevos brotes en E. globulus (cuadro 5), en general, las especies del género Eucalyptus son altamente sensibles a la concentración y tipo de citoquinina utilizadas (Nugent et al. 2001, Larson et al. 2006), afectando la cantidad y calidad de brotes inducidos (Trindade et al. 1990). El efecto del 6-bencilaminopurina en la tasa de proliferación de E. globulus concuerda con los trabajos obtenidos por Castro y González (2002) y Sotelo y Monza (2007), obteniendo además de mayores tasas de proliferación y brotes más vigorosos. Según Trindade et al. (1990) es importante evitar un excesivo aumento en las concentraciones de 6-bencilaminopurina, debido a que tiempos prolongados de exposición a 6-bencilaminopurina pueden producir un agotamiento fisiológico del material, lo que podría causar una disminución de las tasas de proliferación en subcultivos sucesivos, efectos que fueron también reportados por Gómez et al. (2007) en E. globulus.

$\mathrm{Al}$ agregar polivinilpirrolidona en el cultivo con sistema de inmersión temporalde E. globulus aumentó el número de brotes sin afectar la calidad de los tejido (cuadro 5). Eso se puede deber a la inhibición de componentes polifenólicos que, según Trigiano y Gray (2000), causan disminución en el crecimiento y desarrollo. Pero el excesivo aumento de la concentración de polivinilpirrolidona en el medio de cultivo provocó una disminución en la tasa de proliferación, esto podría estar relacionado a la actividad de la polifenoloxidasa, ya que según los resultados obtenidos por Bonga y Durzan (1987) el polivinilpirrolidona agregado al medio de cultivo con el objetivo de reducir la actividad de la polifenoloxidasa inhibe el crecimiento de E. grandis. Respecto a esto, según Pâques y Boxus (1987), el contenido de fenoles y por tanto el grado de lignificación de los tejidos, proceso opuesto a la hiperhidratación, depende de la relación carbono/nitrógeno. En este estudio, la hiperhidratación se vio influida por la concentración de macronutrientes y el nivel de sacarosa del medio (cuadros 4 y 5), de manera que se reafirma la relación del contenido de carbohidratos y nutrientes sobre el nivel del hiperhidratación descrito por estos autores. El mismo razonamiento anterior podría explicar el aumento de la concentración de polivinilpirrolidona que provocó además, una aumento de la masa seca/masa fresca de los brotes obtenidos, ya que, según los mismos autores, esta sustancia interfiere con el metabolismo de los fenoles alterando el proceso de lignificación y por tanto, podría afectar los niveles de contenido de agua versus materia seca de los mismos.

\section{CONCLUSIONES}

La tasa de multiplicación de microtallos de E. globulus es significativamente mayor al aumentar el tiempo de inmersión de 1 a 2 minutos, así como al suplementar el medio de cultivo con 4,4 $\mu \mathrm{M}$ de 6-bencilaminopurina. Por otra parte, la tasa de multiplicación decae si la frecuencia de inmersión disminuye de ciclos cada $12 \mathrm{~h}$ a ciclos cada 48 h. La hiperhidratación de los tejidos aumenta al elevar la concentración de los macronutrientes y sacarosa, sin ser afectada por el nivel de antioxidante agregado al medio. 


\section{AGRADECIMIENTOS}

Los autores agradecen a la Comisión Nacional de Investigación Científica y Tecnológica (CONICYT) y a la Escuela de Graduados de la Universidad de Concepción.

\section{REFERENCIAS}

Berthouly M, H Etienne. 2005. Temporary immersion system: A new concept for use liquid medium in mass propagation. In Hvoslef-Eide A, W Preil eds. Liquid culture systems for in vitro plant propagation. Dordrecht, Netherlands. SpringerVerlag. p. 165-196.

Bonga JM, J Durzan. 1987. Cell and tissue culture in forestry. Dordrecht, Netherland. Martinus Nijhoff Publishres. 425 p.

Bouman H, A Tiekstra. 2005. Adaptations of mineral composition of mineral tissue culture media on the basis of plant analysis and composition of hidroponic substrates. In Hvoslef-Eide A, W Preil eds. Liquid culture systems for in vitro plant propagation. Dordrecht, Netherlands. SpringerVerlag. p. 493-508.

Castro D, J González. 2002. Eucalyptus (Eucalyptus grandis Hill. ex Maiden.) en el sistema de inmersión temporal. Agricultura Técnica 62(1): 68-78.

Escalona M, JC Lorenzo, B González, M Daquinta, Z Fundora, CG Borroto, D Espinosa, E Arias, ME Aspiolea. 1998. Pineapple (Ananas comosus L. Merr.) micropropagation in temporary immersion systems. Plant Cell Reports 18(9): 743-748.

Etienne H, M Berthouly. 2002. Temporary immersion systems in plant micropropagation. Plant Cell, Tissue and Organ Culture 69(3): 215-231.

Fujiwara K, T Kozai. 1995. Physical micro-environment and its effects. In Aitken-Christie J, T Kozai, MAL Smith eds. Automation and environmental control in plant tissue culture. Dordrecht, Netherlands. Academic Publishers. p. 319-369.

Gómez C, M Uribe, D Ríos, M Sánchez-Olate. 2006. Inducción de callo embriogénico en Eucalyptus globulus Labill. Interciencia 31(10): 734-738.

Gómez C, D Ríos, M Sánchez-Olate. 2007. Efecto del subcultivo sucesivo sobre la caulogénesis adventicia de Eucalyptus globulus. Bosque 28(1): 13-17.

Larson C, C Gómez, M Sánchez-Olate, D Ríos. 2006. Inducción de caulogénesis indirecta en Eucalyptus globulus Labill. Bosque 27(3): 250-257.
Jackson MB. 2003. Aeration stress in plant tissue cultures. Bulgarian Journal of Plant Physiology Special Issue.96-105.

Martre P, L Dominique, D Just, C Teisson. 2001. Physiological effects of temporary immersion on Hevea brasiliensis callus. Plant Cell, Tissue and Organ Culture 67(1): 25-35.

McAlister B, J Finnie, MP Watt, F Blakeway. 2005. Use of temporary immersion bioreactor system (RITA $\left.{ }^{\circledR}\right)$ for production of commercial Eucalyptus clones in Mondi Forest (SA). Plant Cell, Tissue and Organ Culture 81(3): 347-358.

Murashige T, F Skoog. 1962. A revised medium for rapid growth and bioassays with tobacco tissue cultures. Plant Physiology 15: 473-497.

Nugent G, SF Chandler, P Whiteman, TW Stevenson. 2001. Adventitious Bud Induction. In Eucalyptus globulus Labill. In Vitro Cellular \& Developmental Biology - Plant 37: 388391.

Paek KY, D Chakrabarty, EJ Hahn. 2005. Application of bioreactor systems for large scale production of horticultural and medical plants. Plant Cell, Tissue and Organ Culture 81(3): 287-300.

Pâques M, PhBoxus. 1987. Vitrification: a review of literature. Acta Horticulturae (ISHS) 212: 155-166.

Pierik R.L.M. 1997. In Vitro Cultures of higher plants. Dordrecht, Netherlands. Martinus Nijhoff Publishers. 326 p.

Preil W. 2005. General introduction: a personal reflection on the use of liquid media for in vitro culture. In Hvoslef-Eide A, W Preil eds. Liquid Culture Systems for in vitro Plant Propagation. Dordrecht, Netherlands. Springer-Verlag. p 1-20.

Ramage C. y Williams R. 2002. Mineral nutrition and plant morphogenesis. In Vitro Cellular \& Developmental Biology Plant 38:116-124

Roels S, M Escalona, I Cejas, C Noceda, R Rodriguez, M J Canal, J Sandoval y P Debergh. 2005. Optimization of plantain (Musa AAB) micropropagation by temporary immersion system. Plant Cell, Tissue and Organ Culture 82: 57-66

Sotelo M, Monza J. 2007.Micropropagation of Eucalyptus maidenii elite trees. Agrociencia 11(1): 81-89.

Trigiano R, D Gray. 2000. Plant tissue culture concepts and laboratory exercises. Washington DC, USA. CRC Press. 454 p.

Trindade H, Ferreira JG, Pais MS, Aloni R. 1990. The role of citokinin and auxin in rapid multiplication of shoots of Eucalyptus globulus grown in vitro. Australian Forestry 53(3): 221-223.

Ziv M. 2000. Birreactor technology for plant micropropagation. Horticultural Reviews 24: 1-30.

Ziv M. 2005. Simple bioreactors for mass propagation of plants. Plant Cell, Tissue and Organ Culture 81(3): 277-285. 